\title{
Dual control of Shuanghuang Shengbai granule on upstream and downstream signal modulators of CyclinD-CDK4/6 signaling pathway of cell cycle in Lewis-bearing mice with cyclophosphamide- induced myelosuppression
}

This article was published in the following Dove Press journal:

OncoTargets and Therapy

22 March 2013

Number of times this article has been viewed

Xian Gu'

Zhen-ye $\mathrm{Xu} \mathbf{u}^{\prime}$

Ling-yu Zhu'

Li-fang Wang'

Kai Li'

Qiang $\mathrm{Pei}^{2}$

'Longhua Hospital Shanghai University of TCM, Shanghai, People's Republic of China; ${ }^{2}$ The First Affiliated Hospital of Xinxiang Medical University, Weihui, People's Republic of China
Correspondence: Zhen-ye Xu

Tumor Institute of Traditional Chinese Medicine, Longhua Hospital, Shanghai

University of Traditional Chinese

Medicine, Shanghai 200032,

People's Republic of China

Tel +58 835753 II 6

Fax +02 168703877

Email xuzhenyel947@I26.com
Background: This study investigated the dual control mechanism of the Shuanghuang Shengbai granule in modulating the cell cycle in Lewis-bearing mice with cyclophosphamide induced myelosuppression.

Methods: Thirty Lewis-bearing mice were randomly grouped into an untreated group, control group, and treated group. Both treated and untreated groups were intraperitoneally injected with cyclophosphamide to produce a myelosuppression model. Mice in the treated group were fed with the Shuanghuang Shengbai granule ( $40 \mathrm{~g} /$ day) for 6 consecutive days. Standard blood tests and the count of bone marrow nuclear cells were performed, and the cell reproductive cycles of bone marrow and tumors were measured in these mice. In addition, the western blot approach was used to measure the upstream activating signals of CyclinD-CDK4/6 such as c-Myc and CDC25A, the upstream suppression signals such as p16INK4a, and the expression of downstream activated signals such as $\mathrm{Rb}, \mathrm{pRB}$, and $\mathrm{E} 2 \mathrm{~F}$. All of the tested results were validated by reverse transcription quantitative real-time polymerase chain reaction.

Results: The results showed that the Shuanghuang Shengbai granule could elevate the count of leukocyte and bone marrow nuclear cells of Lewis-bearing mice with cyclophosphamide induced myelosuppression. It could also stimulate bone marrow cells to move from G0/G1 phases to $\mathrm{S}$ phase, accelerating the progress of the cell reproductive cycle and increasing the cell proliferation index. Simultaneously, the Shuanghuang Shengbai granule could also suppress cancer cells moving from $\mathrm{G} 0 / \mathrm{G} 1$ phase to $\mathrm{S}$ phase, reducing the proliferation index. The tumor weight of Lewis-bearing mice in the treated group was much less than those of the control group. Expression levels of c-Myc, CDC25A, Rb, pRb, and E2F of bone marrow in Shuanghuang Shengbai granule-treated mice was higher compared to the control group, whereas they were lower in the cancer cells.

Conclusion: The experimental results demonstrate that the Shuanghuang Shengbai granule has dual control on the cell reproductive cycles in cancer cells and bone marrow nuclear cells in Lewis-bearing mice.

Keywords: Shuanghuang Shengbai granule, CyclinD-CDK4/6, c-Myc, Rb, pRb, E2F

\section{Introduction}

Chemotherapy is one of the primary approaches for cancer treatment. Chemotherapy destroys cancer cells anywhere in the body, and they kill cells that are extremely active. Cancer cells are extremely active. However, the fast-dividing cells of the body, such 
as blood cells and the cells lining the mouth, stomach, hair, and intestines, also account for chemotherapy's destructive side effects. ${ }^{1}$ The destruction of normal cells, especially the hematopoietic stem cells, deteriorate the human immune system and significantly suppresses bone marrow function, leading to leucopenia. ${ }^{1}$

During the chemotherapy-induced myelosuppression period, the proliferation of bone marrow cells will help patients recover, and in contrast the proliferation of cancer cells will accelerate cancer growth and aggravate the sickness. Currently, the main drug for chemotherapy-induced myelosuppression is the recombinant human granulocyte colony-stimulating factor injection (rhG-CSF). The rhG-CSF can effectively prevent chemotherapy-induced neutropenia, and enhances the function of mature neutrophils, which is vital for the human body's reactive defense system. ${ }^{1}$

However, recent studies have shown that rhG-CSF also accelerates the growth of cancer cells along with the stimulation of bone marrow to generate blood cells., ${ }^{2,3}$ Therefore, many clinicians have now raised concern about the safety of rhG-CSF injection. It has become important to develop a new drug that can promote the proliferation of hematopoietic stem cells, while simultaneously suppressing the proliferation of cancer cells. Herbal medicine has been shown to restore chemotherapy or irradiation-induced myelosuppression through the stimulation of granulocyte colony-stimulating factor (G-CSF) secretion. Lycium barbarum polysaccharide was shown to promote the peripheral blood recovery of irradiation or chemotherapy-induced myelosuppressive mice, and the effect was attributed to the result of the stimulation of peripheral blood mononuclear cells to produce G-CSF. ${ }^{4}$ In addition, Guo et $\mathrm{al}^{5}$ showed that the promotion of Epo and G-CSF gene expressions in bone marrow could potentially be one of the mechanisms underlying the blood enriching function of the Chinese herb, Siwu Tang.

The cell reproductive cycle is a chronological process that starts from the end of a cell's last mitosis to the end of a cell's current mitosis. A standard cell reproductive cycle is composed of four consecutive phases: the G1 phase (Gap 1 phase), S phase (deoxyribonucleic acid (DNA) synthesis phase); G2 phase (Gap 2 phase); and M phase (mitosis phase). G1 phase, S phase, and G2 phase together are also defined as interphase. By going through the interphase and mitosis phase, a parental cell can complete the whole proliferation process, generating two offspring cells with the same genetic material..$^{6-8}$

The key controlling point of the cell reproductive cycle where proliferation starts is between the G1 and S phases.
The controlling point in mammalian cells is called the "restriction point," which decides whether the cells can go through the G1 phase to the $\mathrm{S}$ phase, so as to start the cell reproductive cycle. ${ }^{9}$ Sub-G1 phase DNA content is suggestive of apoptosis, which is generally detected by flow cytometry analysis. Chemotherapeutic agents like suberoylanilide hydroxamic acid has been shown to significantly inhibit cell cycle progression (sub-G1 arrest) and to induce apoptosis in colon cancer cells. ${ }^{10}$ The whole control process is strictly regulated by internal/external signals of the cells. Cell reproduction signals, such as growth factors, initiate the transaction of multiple genes by variable signal transaction approaches, driving cells to start the reproductive cycle.

The classical approach to relate the signals and the cell restriction point is the signal pathway whose core is CyclinDCDK4/6. When growth signal and early response gene signal reaches the restriction point, the CyclinD expression increases, and then CyclinD and CDK 4/6 together form a complex of CyclinD-CDK 4/6, which has an activated protein kinase, driving the cell cycle to start. In this whole process, upstream signal c-Myc and CDC25A activate the CyclinD-CDK4/6, whereas p16INK4a and p15INKb suppress CyclinD-CDK 4/6. The integration and separation of downstream signal $\mathrm{Rb}$ and $\mathrm{E} 2 \mathrm{~F}$ relies on the activated status of CyclinD-CDK4/6. Therefore, all the molecules on the signal chain act on each other mutually to decide if the cell reproductive cycle can pass the G1 phase and move to next phase (Figure 1).

Professor Zhen-ye Xu from Longhua Hospital, which is affiliated with Shanghai University of Traditional Chinese Medicine, developed the Shuanghuang Shengbai granule by leveraging the yin-yang balance to treat cancer. The new granule has been applied in clinical treatment and has been achieving the objectives in cancer patients. From preclinical trials, ${ }^{1-13}$ it has been established that the Shuanghuang Shengbai granule can diminish chemotherapy-induced myelosuppression and help in the recovery of normal leukocyte count. The clinical effectiveness has proved to be reliable and durable. The Shuanghuang Shengbai granule can stimulate the proliferation of bone marrow cells and it can act positively on the expression of CyclinD-CDK4/6 in the bone marrow.

This study was developed based on the results of previous research, and from the approach of controlling the CyclinD-CDK4/6 signal pathway. We have previously shown that the expressions of CDK4, CDK6, and Cyclin D1 in bone marrow and tumor tissues in the untreated group were 


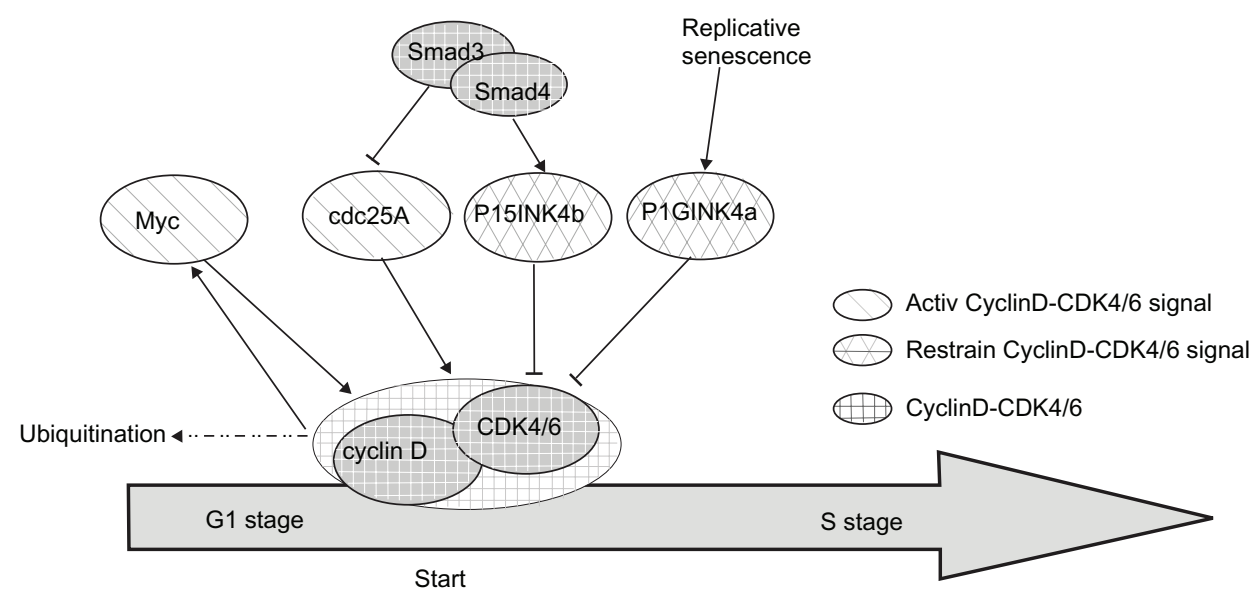

Figure I GI to $S$ phase cell cycle transition regulators. Abbreviations: S, synthesis; GI, Gap I.

higher when compared to the control group. ${ }^{13}$ Compared to the untreated group and the control group, the expressions of CDK4, CDK6, and Cyclin D1 were higher in the bone marrow of the treated group; however, the expressions of CDK4, CDK6, and Cyclin D1 in tumor tissues were lower when compared to the untreated and control groups. ${ }^{14}$ The current study aimed to further investigate the impact of the Shuanghuang Shengbai granule on extenuating chemotherapy-induced myelosuppression, and to argue the nature of Chinese medicine theory to treat bone marrow suppression by enhancing kidney function.

\section{Materials and methods Experimental drug}

The Shuanghuang Shengbai granule consists of Astragalus, Polygonatum, Drynaria, Ligustrum lucidum, Radices trichosanthis, and Herba epimedii. The drug was manufactured by Shanglian Pharmaceutical Company (Shanghai Shanglian Pharmaceutical Co, Ltd, Shanghai, People's Republic of China; after being authorized by Professor Xu Zhen-ye) with a unit weight of $15 \mathrm{~g} / \mathrm{bag}$. Cyclophosphamide (CTX) injection was supplied by Jiangsu Hengrui Medicine Company (Jiangsu Hengrui Medicine Co, Ltd, Jiangsu, People's Republic of China). The drug dosage was based on the previous research on the Shuanghuang Shen baigranule. ${ }^{11-13}$

\section{Reagents and antibodies}

Goat antimouse secondary antibody (c-Myc), goat antirabbit secondary antibody N-myc, L-myc, p16INK4a, Rb, E2F, and rabbit antigoat secondary antibody (CDC25A, p15INK4b, and $\mathrm{p}-\mathrm{Rb}$ ) were purchased from Sigma Chemicals (Sigma Chemicals, Perth, Australia).

\section{Animal model and experimental groups}

The setup of the previous experiment used 30 specific pathogen free $\mathrm{C} 57 \mathrm{BL} / 6 \mathrm{~J}$ inbred male mice, weighing 18 21 g each, license number 2009-0003. ${ }^{15}$ All the mice were purchased from the Shanghai Experimental Animal Co, Ltd (Shanghai, People's Republic of China), and they were raised in the specific pathogen free-class breeding room in the Shanghai University of Traditional Chinese Medicine. The Lewis lung cancer mice were donated from the Shanghai Chest Hospital (Shanghai, People's Republic of China).

Lewis carcinoma of lung oncocyte of mice cancer cells were used for inoculation. These were solid tumor cells with tumor growth characteristics. According to the standard experimental process, after 14 days of passaging, the Lewis lung cancer mice were killed by breaking their necks and they were disinfected by $75 \%$ alcohol. The tumor was peeled off under sterile conditions. The mice were operated on ice, the necrotic part was removed, and the tumor tissue was cut into little pieces by disinfected scissors. A total of $4 \mathrm{~mL}$ of saline was added into a burnisher, and the tumor tissue was ground and filtered. The number of cells was counted by the cell counting chamber under microscope; the tumor cells were adjusted to $1 \times 10^{7}$ cells $/ \mathrm{L}$, inoculated into the left armpit of C57BL/6 J mice by a $1 \mathrm{~mL}$ syringe, at a dose of $0.2 \mathrm{~mL}$ per mouse.

When the tumor in the mouse became palpable, mice with similar tumor sizes were selected and randomly segmented into either an untreated group, a control group, or a treated group with ten mice in each group. Each group, kept in separate cages, was medicated separately, and drug dose was decided as per previous research and methods. ${ }^{16}$

The control group and treated groups were injected with intraperitoneal CTX (2 mL per mouse). These two groups 
represented the myelosuppression model. The untreated group was intraperitoneally injected with normal saline ( $2 \mathrm{~mL}$ per mouse, once a day for 3 consecutive days). Mice in the treated group were fed with the Shuanghuang Shengbai granule $(0.4 \mathrm{~mL} / \mathrm{day}$, which equals to $40 \mathrm{~g}$ of the raw drug) immediately after intraperitoneal injection. For evaluation, mice in the untreated group and control group were fed with normal saline ( $0.4 \mathrm{~mL} /$ day, once a day for 6 consecutive days). After administration of the medication, blood samples were collected through the tail vein of the mice on days 1,4 , and 6 from all three groups. On the last day, and 2 hours after feeding, the eyeball of every mouse in all three groups was taken to collect blood samples, and all the mice were killed by breaking their necks. After killing, the bilateral femur and tibia of each mouse was quickly collected under sterile conditions for further study.

The bone marrow suppression model of Lewis-bearing mice is as follows: Lewis-bearing mice similar in weight and tumor size were selected after 14 days of tumor passaging, and they were intraperitoneally injected with $0.01 \mathrm{~g} / \mathrm{L}$ of CTX, or $0.2 \mathrm{~mL} /$ day, which was equal to $100 \mathrm{mg} / \mathrm{kg} /$ day, The mice were injected for 3 consecutive days to prepare the model.

\section{Leukocyte and bone marrow nucleated cel counting}

The leukocyte and bone marrow nuclear cell (BMNC) counts were done by the automatic blood cell analyzer and microscopic cell counting plate, respectively.

\section{Measurement of cell reproductive cycle progress and the cell proliferation index (PI)}

Tumor and bone marrow was collected and made into a single cell suspension separately, then the cell number was adjusted to $1 \times 10^{6} / \mathrm{L}$ fixed by $95 \%$ ethanol. Propidium iodide staining was used to dye the cells. The process of the cell reproductive cycle was monitored by flow cytometry cases, and the recorded data was used to calculate the proportion of cells at G0/G1 phase and PI. PI was calculated using the formula:

$$
\mathrm{PI}=(\mathrm{S}+\mathrm{G} 2 \mathrm{M}) /(\mathrm{G} 0 / \mathrm{G} 1+\mathrm{S}+\mathrm{G} 2 \mathrm{M}) \times 100 \%
$$

Total ribonucleic acid was isolated from the cells by acid guanidiniumthiocyanate-phenol-chloroform extraction. Reverse transcription was carried out on $1 \mu \mathrm{g}$ of total ribonucleic acid for 1 hour at $42^{\circ} \mathrm{C}$ using oligo-dT primers and Moloney Murine Leukemia Virus reverse transcriptase, according to the vendor's instruction (Shanghai Biotech Company, Shanghai, People's Republic of China). Polymerase chain reaction (PCR) with Taq DNA polymerase was performed for 29 cycles for c-Myc, 30 cycles for CDC25A, 28 cycles for $\mathrm{p} 16 \mathrm{INK} 4 \mathrm{a}, 29$ cycles for $\mathrm{Rb}, 31$ cycles for $\mathrm{pRb}$, and 28 cycles for $\mathrm{E} 2 \mathrm{~F}$ using the following protocol: $95^{\circ} \mathrm{C}$ for 60 seconds, $95^{\circ} \mathrm{C}$ for 10 seconds, and $60^{\circ} \mathrm{C}$ for 30 seconds. The PCRs were carried out using primers for c-Myc (sense primer: 5'-TCTCCATCCTATGTTGCGGTC-3'; antisense primer: 5'-TCCAAGTAACTCGGTCATCATCT-3'), for the CDC25A (sense primer: 5'-CCGATTCAGGTTTCT GTCTAG-3'; antisense primer: 5'-GAGGTGAAAGGT GTCGTGGT-3'), for the p16INK4a (sense primer: 5'-CATCTGGAGCAGCATGGAGTC-3'; antisense primer: $5^{\prime}$-CGTTGCCCATCATCATCACCT-3'), for the Rb (sense primer: 5'-ACAACCCAGCAGTGCGTTATC-3'; antisense primer: 5'-ACCAGGTCATCTTCCATCTGT-3'), for the pRb (sense primer: 5'-TCACCCAGGACACCACCATG-3'; antisense primer: $5^{\prime}$-TCCCTGAGAACCTCCCTGTG-3'), or for the E2F (sense primer: 5'-CTCGACTCCTCG CAGATCG-3'; antisense primer: 5'-GATCCAGCCTC CGTTTCACC-3').

All PCR products (c-Myc-369 bp; CDC25A-413 bp; p16INK4a-217 bp; Rb-371 bp; pRb-511 bp; E2F-217 bp) were analyzed by electrophoresis in $2 \%$ agarose gels. Real time quantitative PCR (RT-qPCR) was performed in a StepOnePlus ${ }^{\text {TM }}$ Real-Time PCR Systems (Life Technologies, Carlsbad, CA, USA) in a mixture containing SYBR ${ }^{\circledR}$ Green PCR Master Mix (SYBR ${ }^{\circledR}$ Green qPCR Kit, Sigma-Aldrich, St Louis, MO, USA); PCR Core System was obtained from Applied Biosystems Co (Life Technologies).

\section{Western blotting}

Cells were lysed in icecold lysis buffer (phosphate buffered saline with 1\% Triton ${ }^{\mathrm{TM}}$ (Sigma-Aldrich Company, St Louis, MO, USA), $10 \mu \mathrm{g} / \mathrm{mL}$ of phenylmethanesulfonylfluoride, $10 \mu \mathrm{g} / \mathrm{mL}$ of leupeptin, and $10 \mu \mathrm{g} / \mathrm{mL}$ of aprotinin). Samples were centrifuged for 20 minutes at $8000 \mathrm{~g}$ at $4^{\circ} \mathrm{C}$ and clear supernatants were collected. A total of $30 \mu \mathrm{g}$ of protein were loaded on $12 \%$ sodium dodecyl sulfate polyacrylamide gel electrophoresis followed by overnight electro transfer to nitrocellulose membrane Protran ${ }^{\mathrm{TM}}$ (PerkinElmer, Waltham, MA, USA). After blocking in 5\% nonfat milk for 1 hour at room temperature, membranes were probed with polyclonal antibodies against c-Myc, CDC25A, p16INK4a, Rb, pRb, E2F (Santa Cruz) overnight at $4{ }^{\circ} \mathrm{C}$ followed by horseradish peroxidase-linked secondary antibodies (Santa Cruz) for 
Table I The count of leukocytes (mean \pm standard error)

\begin{tabular}{llll}
\hline Group & First day & Fourth day & Sixth day \\
\hline Treated & $6.76 \pm 1.77$ & $3.40 \pm 0.88^{\mathrm{a}, \mathrm{b}}$ & $3.28 \pm 0.73^{\mathrm{a}, \mathrm{b}}$ \\
Control & $6.48 \pm 1.05$ & $2.86 \pm 0.57^{\mathrm{b}}$ & $2.02 \pm 0.70^{\mathrm{b}}$ \\
Untreated & $7.29 \pm 1.06$ & $6.31 \pm 1.70$ & $5.87 \pm 1.37$ \\
\hline
\end{tabular}

Notes: ${ }^{a}$ Compared with the control group, $P<0.05$; ${ }^{\text {c} c o m p a r e d ~ w i t h ~ t h e ~ u n t r e a t e d ~}$ group, $P<0.05$.

45 minutes at room temperature. Antibodies were diluted in Tris-buffered saline with $5 \%$ bovine serum albumin. Visualization was performed using SuperSignal West Pico Chemiluminescent Substrate according to the vendor's protocol (Thermo Fisher Scientific, Waltham, MA, USA).

\section{Statistical analysis}

All data were represented by the mean \pm standard error of at least three independent experiments. Statistical analysis was performed by one-way analysis of variance, and further post hoc testing was performed using the statistical software SPSS 17.0 (IBM Corporation, Armonk, NY, USA); a $P$-value of $<0.05$ was considered to be statistically significant.

\section{Results}

\section{Leukocyte and BMNC count}

As presented in Table 1, the leukocyte count in each group on day 1 was similar; however, the leukocyte count in the treated group on days 4 and 6 was higher than those in the control group, especially on day $6(P<0.05)$. The results showed the elevation of the leukocyte count of Lewisbearing mice with CTX-induced myelosuppression in the Shuanghuang Shengbai granule group.

Bone marrow is the primary blood-forming organ; the count of BMNC is an important indicator of the response of hematopoietic function of bone marrow cells. The count of BMNC of Lewis-bearing mice with CTX is much less than those of the untreated group $(P<0.01)$ (Table 2), which explains the likelihood of killing the bone marrow cells by CTX. The count of BMNC of Lewis-bearing mice with CTX is much less than those of the untreated group $(P<0.01)$,

Table 2 The count of BMNC (mean \pm standard error)

\begin{tabular}{lll}
\hline Group & $\begin{array}{l}\text { Number } \\
\text { of tests }\end{array}$ & $\begin{array}{l}\text { BMNC }\left(\times 10^{7} \text { per }\right. \\
\text { femur })\end{array}$ \\
\hline Treated & 10 & $0.80 \pm 0.08^{\mathrm{a}, \mathrm{b}}$ \\
Control & 10 & $0.56 \pm 0.07^{\mathrm{b}}$ \\
Untreated & 10 & $1.28 \pm 0.8$ \\
\hline
\end{tabular}

Notes: aCompared with the control group, $P<0.01$; ${ }^{b}$ compared with the untreated group, $P<0.01$.

Abbreviation: BMNC, bone marrow nuclear cells.
Table 3 Cell cycle distribution and the PI of bone marrow cells (mean \pm standard error)

\begin{tabular}{lllll}
\hline Group & G0/GI (\%) & G2/M (\%) & S (\%) & PI $\left(\times \mid \mathbf{0}^{-1}\right)$ \\
\hline Treated & $53.59 \pm 2.18^{\mathrm{a}, \mathrm{b}}$ & $15.23 \pm 7.22$ & $31.18 \pm 6.65$ & $4.64 \pm\left. 0.2\right|^{\mathrm{a}, \mathrm{b}}$ \\
Untreated & $61.06 \pm 3.57^{\mathrm{a}}$ & $12.55 \pm 3.72$ & $26.39 \pm 3.62$ & $3.90 \pm 0.30^{\mathrm{a}}$ \\
Control & $69.83 \pm 2.53$ & $4.51 \pm 2.73$ & $25.67 \pm 4.47$ & $3.01 \pm 0.25$
\end{tabular}

Notes: aCompared with the control group, $P<0.05$; ${ }^{\text {ccompared }}$ with the untreated group, $P<0.05$.

Abbreviations: PI, proliferation index; G0, Gap 0 phase; GI, Gap I phase; G2, Gap 2 phase; $M$, mitosis phase; $S$, synthesis phase.

indicating the promotion and proliferation of bone marrow cells with the Shuanghuang Shengbai granule (Table 2).

\section{Distribution of cells in different phases of the cell cycle}

The cell reproductive cycle is a process of a cell that completes in one mitosis division. In the G1 phase, the cells are ready to divide, and this is the critical point in deciding whether a cell can move to the division phase. The percentage of cells at the G1 phase is an important indicator for measuring the activity of cell proliferation; the lower the percentage of cells in the G1 phase compared to other phases in the cell cycle implies active cell proliferation. The G0/G1 percentage in the treated group $(53.59 \%)$ in bone marrow cells was significantly lower than that of control group (69.83\%); PI was found to be significantly higher $-4.64 \times 10^{-1}$ in contrast to $3.01 \times 10^{-1}$ in the control group (Table 3). The main hypothesis surrounding this result is that the bone marrow cells have undergone reactive hyperplasia once they were seriously damaged by the CTX application.

Uncontrolled proliferation is the core characteristic of cancer cells. Chemotherapy kills cancer cells mainly by damaging cell division and proliferation in order to shrink the tumor. The percentage of cancer cells at the G0/G1 phase in the treated group (51.62\%) where chemotherapy drugs were stopped, but the Shuanghuang Shengbai granule that was continuously used, was higher than in both the untreated group (37.13\%) and the control group (44.74\%) (Table 4). PI was lowest as well, which indicates that the proliferation of cancer cells was suppressed in the treated

Table 4 Cell cycle distribution and PI of cancer cells (mean \pm standard error)

\begin{tabular}{lllll}
\hline Group & G0/G I (\%) & G2/M (\%) & S (\%) & PI $\left(\times 1 \mathbf{0}^{-1}\right)$ \\
\hline Treated & $51.62 \pm 3.65^{\mathrm{a}, \mathrm{b}}$ & $2.20 \pm 4.64$ & $42.53 \pm 9.35$ & $4.62 \pm 0.49^{\mathrm{a}, \mathrm{b}}$ \\
Untreated & $37.13 \pm 3.72^{\mathrm{a}}$ & $5.31 \pm 9.30$ & $50.11 \pm 10.26$ & $5.92 \pm 0.76^{\mathrm{a}}$ \\
Control & $44.74 \pm 2.40$ & $1.15 \pm 3.63$ & $51.64 \pm 5.78$ & $5.32 \pm 0.30$ \\
\hline
\end{tabular}

Notes: a Compared with the control group, ${ }^{*} P<0.05$; ${ }^{b}$ compared with the untreated group, $P<0.05$.

Abbreviations: PI, proliferation index; G0, Gap 0 phase; GI, Gap I phase; G2, Gap 2 phase; $M$, mitosis phase; $S$, synthesis phase. 
Table 5 The effect of the Shuanghuang Shengbai granule on tumor weight (mean \pm standard error)

\begin{tabular}{lll}
\hline Group & Sample (N) & Weight of tumor \\
\hline Treated & 10 & $1.28 \pm 0.12^{*}$ \\
Control & 10 & $1.30 \pm 0.20^{*}$ \\
Untreated & 10 & $1.98 \pm 0.35$
\end{tabular}

Note: Compared with the control group, $P<0.05$.

group $(P<0.05)$. The percentage of cancer cells at the G0/ G1 phase in the control group was lower than in the untreated group, whereas PI was increased. The result demonstrates that the proliferation of cancer cells accelerated after withdrawing the chemotherapy drug (Table 4).

\section{Tumor weight reduction}

This research observed the weight of the tumors in all three groups. Tumor weight reduction is one of the main indicators for the success of cancer treatment; the larger the tumor, the worse the prognosis. The results showed that the treated group had significantly lower mean tumor weight compared to the control group $(P<0.05)$ (Table 5). The results indicated that the Shuanghuang Shengbai granule had definite suppression effects on tumor growth.

\section{Expression of upstream}

\section{and downstream modulators} of the CyclinD-CDK4/6 signaling pathway c-Myc and CDC25A are the upstream activating signals of CyclinD-CDK4/6. The expression of c-Myc and CDC25A in bone marrow was significantly increased in the treated group and control group, when compared to the untreated group $(P<0.05)$. The expression levels of c-Myc and CDC25A in bone marrow were also higher in the treated group compared to the control group $(P<0.05)$. Expression in cancer cells in the control group significantly increased, whereas it decreased in the treatment group $(P<0.05)$ (Table 6). Western blot analysis showed similar results (Figures 2 and 3 ).

$\mathrm{p} 16 \mathrm{INK} 4 \mathrm{a}$ and $\mathrm{p} 15 \mathrm{INK} 4 \mathrm{~b}$ are the upstream suppression signals of CyclinD-CDK4/6. RT-qPCR analytical results showed no statistically significant differences between the

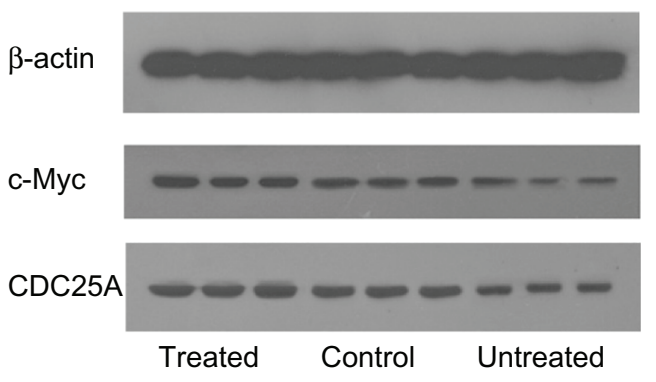

Figure 2 Western blot analysis of c-Myc and CDC25A expression in bone marrow cells.

Note: Western blot analysis showing the expression of c-Myc and CDC25A in bone marrow cells for all three experimental groups.

relative expression of p16INK4a and p15INK4b among the three groups, both in the bone marrow and cancer cells $(P<0.05)$. Western blot analysis showed similar results (Table 7; Figures 4 and 5).

$\mathrm{Rb}, \mathrm{pRb}$, and $\mathrm{E} 2 \mathrm{~F}$ are the downstream signals activated by CyclinD-CDK4/6. The integration and separation usually relies on the activated status of CyclinD-CDK4/6. From the RT-qPCR analytical results, the expression of $\mathrm{Rb}, \mathrm{pRb}$, and $\mathrm{E} 2 \mathrm{~F}$ in bone marrow was significantly higher in the treatment group and control group compared to the untreated group $(P<0.05)$. Also, compared to the control group, the expression in the treatment group was significantly higher $(P<0.05)$. In contrast, the expression of $\mathrm{Rb}, \mathrm{pRb}$, and $\mathrm{E} 2 \mathrm{~F}$ in cancer cells among all the groups was similar, and there were no statistically significant differences $(P>0.05)$. Western blot analysis showed similar results (Tables 8 and 9; Figures 6 and 7).

\section{Discussion}

The present study sheds light on the potential effects of the Shuanghuang Shengbai granule on the recovery of cancer patients from myelosuppression, by stimulating the bone marrow cell reproductive cycle, and by inhibiting the cancer cell reproductive cycle.

The current Lewis-bearing mice experimental approach established the dual control ability of the Shuanghuang Shengbai granule and its effect on CyclinD-CDK4/6's upstream (c-Myc, CDC25A) and downstream signals ( $\mathrm{Rb}$, $\mathrm{pRb}, \mathrm{E} 2 \mathrm{~F})$. The experimental results revealed the increased

Table 6 Relative expression of c-Myc and CD25A in bone marrow and cancer cells (mean \pm standard error)

\begin{tabular}{llll}
\hline Group & c-Myc & & CDC25A \\
\cline { 2 - 3 } & Bone marrow cells & Cancer cells & Bone marrow cells \\
\hline Treated & $0.359 \pm 0.012^{\mathrm{a}, \mathrm{b}}$ & $0.174 \pm 0.033^{\mathrm{a}, \mathrm{b}}$ & $0.544 \pm 0.046^{\mathrm{a}, \mathrm{b}}$ \\
Control & $0.252 \pm 0.019^{\mathrm{b}}$ & $0.367 \pm 0.0209^{\mathrm{b}}$ & $0.129 \pm 0.03 \mathrm{I}^{\mathrm{a}, \mathrm{b}}$ \\
Untreated & $0.127 \pm 0.012$ & $0.253 \pm 0.022$ & $0.375 \pm 0.045^{\mathrm{b}}$ \\
\hline
\end{tabular}

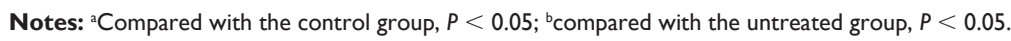




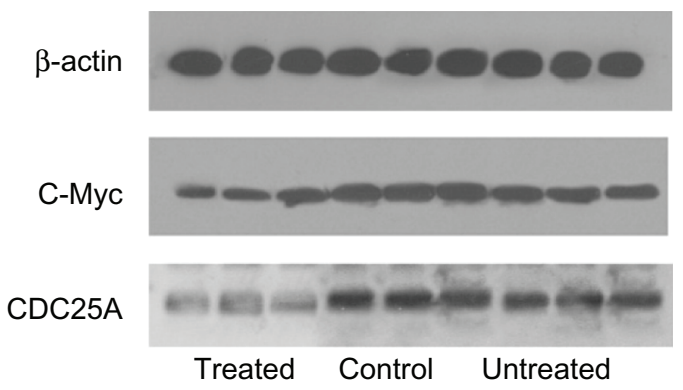

Figure 3 Western blot analysis of c-Myc and CDC25A expression in cancer cells. Note: Western blot analysis showing expression of c-Myc and CDC25A in cancer cells for all three experimental groups.

expression of c-Myc, CDC25A, Rb, pRB, and E2F of the bone marrow in the Shuanghuang Shengbei granule-treated mice group, and decreased expression of these proteins in the cancer cells, explaining the effectiveness of the Shuanghuang Shengbei granule in controlling myelosuppression. The cancer growth and myelosuppression indicates an imbalance in the cell reproductive cycle. Cancer growth represents an over activated cell cycle, whereas myelosuppression represents an under activated cell cycle.

The mechanism of the cell reproductive cycle is controlled by $\mathrm{CDK} /$ cyclin, which is composed of the catalytic subunit, $\mathrm{CDK}$ and the regulatory subunit, cyclin. The gene coding for CDKs are highly conserved from yeasts to human beings. Mammalian CyclinD1/CDK4 complexes can also stimulate the growth of the Drosophila cell. ${ }^{17}$

CDC25A, a dual-specificity protein phosphatase, is a member of the $\mathrm{CDC} 25$ family of phosphatases. It is required for the progression of phases from the G1 to the $\mathrm{S}$ phase of the cell cycle. CDC25A removes the inhibitory phosphorylation incyclin-dependent kinases, such as CDK2, CDK4, and CDK6, and positively regulates the activities of CDKs that lead to cell cycle progression. CDC25A also acts as an apoptosis regulator. The over expression of CDC25A promotes tumorigenesis, and is frequently observed in various types of cancer. ${ }^{18}$

The proto-oncogene c-Myc encodes a transcription factor, which plays a critical role in the regulation of cellular proliferation, differentiation, and apoptosis. It has also been found to be deregulated in several forms of human

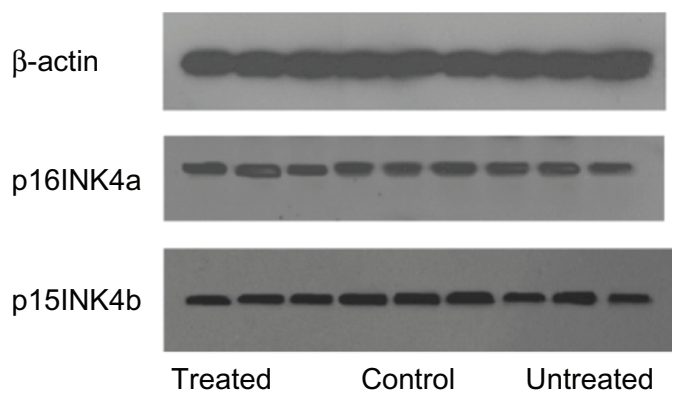

Figure 4 Western blot analysis of pI6INK4a and pI5INK4b expression in bone marrow cells.

Note: Western blot analysis showing the expression of pI6INK4a and pI5INK4b in bone marrow cells for all three experimental groups.

and experimental tumors. Miliani et al showed that CDK4 is one of the critical downstream genes involved in c-Myc carcinogenesis. Their results showed that CDK4 inhibition in K5-Myc transgenic mice resulted in the complete inhibition of tumor development, suggesting that CDK4 is a critical mediator of tumor formation induced by deregulated Myc. ${ }^{19}$ Mateyak et $\mathrm{al}^{20}$ revealed that c-Myc regulates CyclinD/ CDK4 and CDK6 activity, but affects cell cycle progression at multiple independent points. c-Myc-/- cells showed a 12-fold reduction in the activity of CyclinD1/CDK4 and CDK6 complexes during the G0 to S transition.

In 2001, three scientists won the Nobel Prize by discovering this core control mechanism of the cell reproductive cycle. ${ }^{21}$ The integration of CDK4, CDK6, and CyclinD is necessary to initiate the G1 phase. The expression of CDK increases with the spilt of hematopoietic cells; however, the increase of CDK expression has a negative correlation with the growth of cancer cells.2.

Scientists have already observed the over expression of CyclinD in cancers such as breast cancer and esophageal cancer, with the expression having a negative correlation with prognosis. ${ }^{23,24}$ In a Lewis mice experiment, mice harboring defective CyclinD mutant cells were less prone to develop breast cancer when compared to normal mice. When the CyclinD defective mice mated with cancer-sensitive mice, their offspring still had a reduced chance of developing cancers. ${ }^{25}$ In 2004, the Dana-Farber Cancer Institute (Boston, MA, USA) tested the mice lacking CyclinD1, D2, and

Table 7 Relative expression of pI6INK4a and pI5INK4b in bone marrow and cancer cells (mean \pm standard error)

\begin{tabular}{|c|c|c|c|c|}
\hline \multirow[t]{2}{*}{ Group } & \multicolumn{2}{|l|}{ pI6INK4a } & \multicolumn{2}{|l|}{ pI5INK4b } \\
\hline & Bone marrow cells & Cancer cells & Bone marrow cells & Cancer cells \\
\hline Treated & $0.297 \pm 0.053$ & $0.393 \pm 0.017$ & $0.331 \pm 0.026$ & $0.356 \pm 0.005$ \\
\hline Control & $0.375 \pm 0.029$ & $0.327 \pm 0.052$ & $0.349 \pm 0.023$ & $0.264 \pm 0.035$ \\
\hline Untreated & $0.379 \pm 0.041$ & $0.351 \pm 0.038$ & $0.287 \pm 0.083$ & $0.331 \pm 0.057$ \\
\hline
\end{tabular}




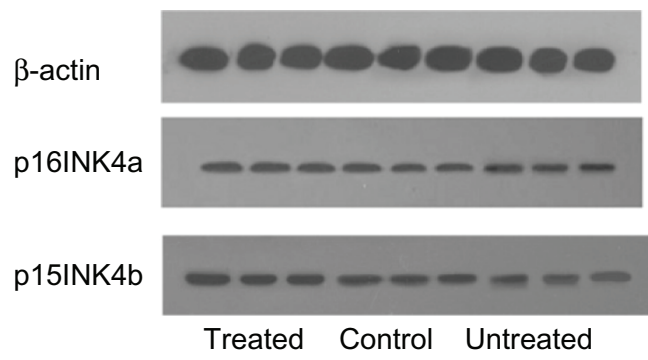

Figure 5 Western blot analysis of pI6INK4a and pI5INK4b expression in cancer cells.

Note: Western blot analysis showing the expression of pI6INK4a and pI5INK4b in cancer cells for all three experimental groups.

D3 genes. ${ }^{26}$ The test results showed the formation of normal embryo cells even after introducing oncogenes to embryo cells of mice without CyclinD.${ }^{19}$ In contrast, normal mice with the CyclinD gene were found to be more prone to developing cancer if their embryo cells were inserted with oncogenes. ${ }^{26}$ In addition, with the decrease of cancer susceptibility, all mice embryos showed abnormal insufficiency of hematopoietic cells, causing them to be pale, anemic, and finally leading to death. ${ }^{26}$

According to recent cell cycle research, over activated $\mathrm{CDK} /$ Cyclin causes the growth and development of cancer; chemotherapy drugs not only suppress the cancer cell's reproductive cycle, but also suppress the split and growth of marrow hematopoietic cells, which finally cause insufficient expression of CDK/Cyclin in marrow cells and blood disorders. ${ }^{27}$ Therefore, it is ideal that a drug used to treat myelosuppression is required to be able to decrease the expression of $\mathrm{CDK} / \mathrm{Cyclin}$ in cancer cells and increase the expression of CDK/Cyclin in marrow cells.

CyclinD-CDK4/6, and its upstream and downstream signals, generate a complex network that work together to control the cell reproductive process. The phosphorylation of ribosomes release a lot of rested transcription factors, particularly E2F, and theses transcription factors can regulate the expression of multiple genes, which in turn translate into multiple types of proteins required for driving the cell reproductive cycle. ${ }^{28}$ The expression of signals in the signal network whose core is CyclinD-CDK4/6 is the

Table 8 Relative expression of Rb, pRb, and E2F in bone marrow cells (mean \pm standard error)

\begin{tabular}{llll}
\hline Group & $\mathbf{R b}$ & $\mathbf{p R b}$ & $\mathbf{E 2 F}$ \\
\hline Treated & $0.443 \pm 0.023^{\mathrm{a}, \mathrm{b}}$ & $0.341 \pm 0.009^{\mathrm{a}, \mathrm{b}}$ & $0.359 \pm 0.012^{\mathrm{a}, \mathrm{b}}$ \\
Control & $0.368 \pm 0.009^{\mathrm{b}}$ & $0.263 \pm 0.029^{\mathrm{b}}$ & $0.252 \pm 0.019^{\mathrm{b}}$ \\
Untreated & $0.249 \pm 0.020$ & $0.134 \pm 0.031$ & $0.127 \pm 0.012$ \\
\hline
\end{tabular}

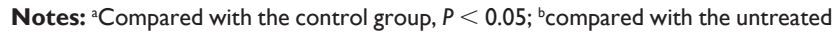
group, $P<0.05$.
Table 9 Relative expression of Rb, pRb, and E2F in tumor cells (mean \pm standard error)

\begin{tabular}{llll}
\hline Group & $\mathbf{R b}$ & $\mathbf{p R b}$ & $\mathbf{E 2 F}$ \\
\hline Treated & $0.304 \pm 0.053$ & $0.248 \pm 0.05 \mathrm{I}$ & $0.257 \pm 0.055$ \\
Control & $0.355 \pm 0.028$ & $0.295 \pm 0.008$ & $0.331 \pm 0.055$ \\
Untreated & $0.265 \pm 0.039$ & $0.245 \pm 0.050$ & $0.253 \pm 0.022$ \\
\hline
\end{tabular}

critical adjustment factor of the cell reproductive cycle, ${ }^{29}$ and of the proliferation and differentiation of bone marrow hematopoietic cells. ${ }^{27}$

Over the past 10 years, many researchers investigated the application of Chinese medicine to treat myelosuppression and many "strengthening-body-resistance -purpose" medicines have been developed. ${ }^{30-32} \mathrm{~A}$ meta-analysis showed the positive impact of Chinese medicine over Western medicine. ${ }^{33}$ Chinese medicine not only increases leukocyte count, but it also helps patients improve their overall quality of life after chemotherapy. This supports Chinese medicine's ability to stimulate bone marrow and induce hematopoiesis, improving quality of life. Chinese medicine, in addition to a strengthening body resistance purpose, also helps marrow stem cells/progenitor cells (or stromal cells) to grow and initiate blood generation. ${ }^{34-37}$ These medicines have the ability to enhance the expression of Cyclin in marrow cells. ${ }^{37}$ Earlier research supports Chinese medicine in treating cancers, suppressing the growth of cancer cells, ${ }^{37-41}$ and in decreasing the expression of CDK/Cyclin in cancer cells. ${ }^{42}$

All of these investigations signify the dual control nature of Chinese medicine on cell growth, stimulating different types of cells to grow in different ways, but at the same time. On a positive note, Chinese medicine could initiate the growth of marrow hematopoietic cells, while also suppressing the growth of cancer cells. The research results are fully aligned

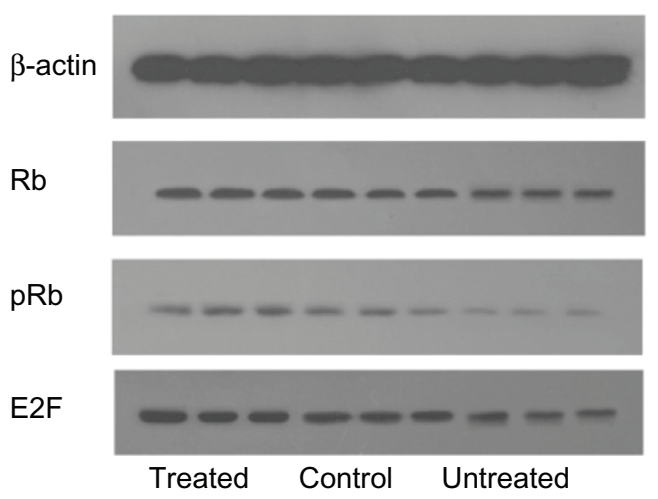

Figure 6 Western blot analysis of Rb, pRb, and E2F expression in bone marrow cells.

Note: Western blot analysis showing the expression of Rb, pRb, and E2F in bone marrow cells for all three experimental groups. 


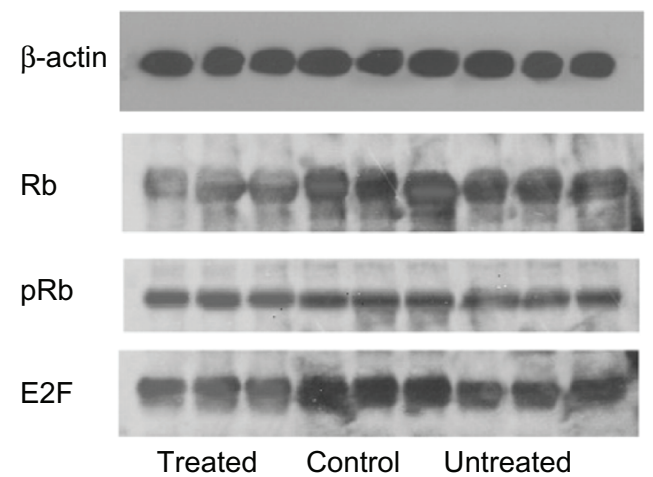

Figure 7 Western blot analysis of Rb, pRb, and E2F expression in cancer cells. Note: Western blot analysis showing the expression of Rb, pRb, and E2F in cancer cells for all three experimental groups.

with the Chinese medicine theory, which applies an overall approach to treat disease while focusing on the recovery balance from Yin and Yang, as well as Qi. ${ }^{43}$

According to traditional Chinese medicine, sickness is caused by the imbalance of Yin and Yang, Qi, and blood in the human body. The purpose of medication is to restore the balance by "reducing the surplus and supply of the weakness." Myelosuppression caused by chemotherapy usually has both "surplus" and a supply of "weakness"-excessive proliferation of cancer cells and insufficient proliferation of bone marrow cells. Bone marrow is defined as "marrow" in traditional Chinese medicine.

Based on the concept of the Yin-Yang balance, the new granule has been applied in clinical treatment and has been achieving positive responses in cancer. The function of the Shuanghuang Shengbai granule focuses on supplying kidney-Qi and generating marrow. Astragalus is sweet and warm, and it supports the supply of kidney-Qi, while Polygonatum is mild so as to replenish the kidneyessence. Furthermore, Ligustrum lucidum can nourish Yin and blood, while Drynaria can strengthen the bone and marrow. ${ }^{44}$ These two drugs can facilitate Astragalus and Polygonatum to enhance their medical impact; therefore, these two drugs are called minister drugs. ${ }^{44}$ The four drugs work mutually to realize the function of supplying kidney-Qi, replenishing kidney essence, and producing the marrow.

Traditionally, Chinese herbal medicines in oncology are based on the principles of strengthening body resistance, suppressing the proliferation of tumor cells, and promoting tumor cell apoptosis. Published literature suggests that the Shuanghuang Shengbai granule significantly increases the white blood cell count, BMNC, and colony forming unit-spleen of model mice. The Shuanghuang Shengbai granule helped the granulocyte and erythrocyte index to recover to a normal level, and it also helped enhance the proliferation of hematopoietic cells, while protecting the bone marrow hematopoietic micro environment from the harm of radiation. In addition, it appears to have an apparent leukogenic function. ${ }^{45,46}$ It has also been shown to offer obvious protecting and treating effects on chemotherapy-induced bone marrow suppression in patients with tumors. ${ }^{47}$

The Shuanghuang Shengbaigranule could be potentially administered to cancer patients whose leukocyte count has been reduced due to chemotherapy, with a dosage of one bag (15 g) once or twice a day. Potential side effects may include diarrhea. The Shuanghuang Shengbai granule accelerates leukocyte production and improves the function of medullary hematopoiesis, reduces tumor size, suppresses the growth of tumors, and it has a dual control effect. Further research in cancer patients is necessary to establish the safety and efficacy of this immensely potent Chinese herb.

\section{Acknowledgments}

This work was supported by grants from the Research Fund for the Doctoral Program of Higher Education (Grant number 20093107110004), The Youth Talent Project of Pudong District (Grant number PWZq2009-1), National Natural Science Fund (Grant number 30973822), and the Research of Shanghai Health Bureau (Grant number 2009Y093).

\section{Disclosure}

The authors reported no conflicts of interest in this work.

\section{References}

1. Zhong RB. Review and outlook of small cell lung cancer. China Oncology. 2008;18:147-151. Chinese.

2. Kirma N, Luthra R, Jones J, et al. Over expression of the colonystimulating factor (CSF-1) and/or its receptor c-fms in mammary glands of transgenic mice results in hyperplasia and tumor formation. Cancer Res. 2004;64(12):4162-4170.

3. Gutschalk CM, Herold-Mende CC, Fusenig NE, Mueller MM. Granulocyte colony-stimulating factor and granulocyte-macrophage colony-stimulating factor promote malignant growth of cells from head and neck squamous cell carcinomas in vivo. Cancer Res. 2006;66(16): 8026-8036.

4. Gong H, Shen P, Jin L, Xing C, Tang F. Therapeutic effects of Lyciumbarbarum polysaccharide (LBP) on irradiation or chemotherapyinduced myelosuppressive mice. Cancer Biother Radiopharm. 2005; 20(2):155-162.

5. Guo P, Liang QD, Hu JJ, Wang JF, Wang SQ. The effect of Siwu Tang on EPO and G-CSF gene expression in bone marrow of irradiated blood deficiency mice. Zhongguo Zhong Yao Za Zhi. 2005;30(15):1173-1176. Chinese.

6. Alberts B, Johnson A, Lewis J, Raff M, Roberts K, Walter P. Molecular Biology of the Cell. 4th ed. New York: Garland Science, Taylor and Francis Group; 2002.

7. Song TD. Medical Cell and Molecular Biology. Beijing: 2003. Chinese. 
8. Zhai ZH, Wang XZ, Ding XM. Zhai in higher education and the higher education press. Cell Biolog. Beijing: 2000. Chinese.

9. Sun PC, Tzao C, Chen BH, Liu CW, Yu CP, Jin JS. Suberoylanilide hydroxamic acid induces apoptosis and sub-G1 arrest of 320 HSR colon cancer cells. J Biomed Sci. 2010;17:76.

10. Takeuchi K, Choi YL, Togashi Y, et al. KIF5B-ALK, a novel fusion oncokinase identified by an immunohistochemistry-based diagnostic system for ALK-positive lung cancer. Clin Cancer Res. 2009;15(9): 3143-3149.

11. Xu ZY, Zhu YW, Zhou WD. Clinical observation on effect of ShuanghuangShengbaigranule and granulocyte-macrophage colony-stimulating factor on chemotherapy induced myelosuppression in tumor patients. Traditional Chinese Medicine. 2003;44:919-921. Chinese.

12. Xu ZY, Zhu YW, Zhou WD. Double Shengbai granules clinical studies of chemotherapy-induced bone marrow suppression and mouse bone marrow ultrastructure observation. Chinese Journal of Integrative Medicine. 2001;7:277-281. Chinese.

13. Wang LF, Xu ZY, Jin CJ, et al. Dual regulation of cell cycles by ShuanghuangShengbaigranule in Lewis-bearing mice with chemotherapy-induced myelosuppression and its mechanism. Zhong Xi Yi Jie He Xиe Bao. 2009;7(5):453-457. Chinese.

14. Wang LF, Xu ZY, Jin CJ. Double Shengbai particle dual regulation of the cell cycle of tumor-bearing mice with Lewis lung cancer. Shanghai Traditional Medicine. 2009;43:56-60. Chinese.

15. Liu JW. Methodology of Pharmacological Experiment. New Technology and Method. Beijing: Chemical Industry Press; 2003.

16. Xu ZY, JUYF. Double Shengbai prescription preventing chemotherapy, bone marrow suppression experimental study. Shanghai University of Traditional Medicine. 1999;13:43-45. Chinese.

17. Datar SA, Galloni M, de la Cruz A, Marti M, Edgar BA, Frei C. Mammalian cyclin D1/Cdk4 complexes induce cell growth in Drosophila. Cell Cycle. 2006;5(6):647-652.

18. Shen T, Huang S. The role of CDC25A in the regulation of cell proliferation and apoptosis. Anticancer Agents Med Chem. 2012;12(6): 631-639.

19. Miliani de Marval PL, Macias E, Rounbehler R, et al. Lack of cyclin-dependent kinase 4 inhibits c-Myc tum origenic activities in epithelial tissues. Mol Cell Biol. 2004;24(17):7538-7547.

20. Mateyak MK, Obaya AJ, Sedivy JM. c-Myc regulates cyclin D-Cdk4 and -Cdk6 activity but affects cell cycle progression at multiple independent points. Mol Cell Biol. 1999;19(7):4672-4683.

21. Balter M, Vogel G. Cycling toward Stockholm. Science. 2001;294(5542): 502-503.

22. Mihara M, Shintani S, Nakahara Y, et al. Over expression of CDK2 is a prognostic indicator of oral cancer progression. Jpn J Cancer Res. 2001;92(3):352-360.

23. Itami A, Shimada Y, Watanabe G, Imamura M. Prognostic value of p27(Kip1) and CyclinD1 expression in esophageal cancer. Oncology. 1999;57(4):311-317.

24. Umekita Y, Ohi Y, Sagara Y, Yoshida H. Over expression of cyclinD1 predicts for poor prognosis in estrogen receptor-negative breast cancer patients. Int J Cancer. 2002;98(3):415-418.

25. Sicinski P, Donaher JL, Parker SB, et al. Cyclin D1 provides a link between development and oncogenesis in the retina and breast. Cell. 1995;82(4):621-630.

26. Kozar K, Ciemerych MA, Rebel VI, et al. Mouse development and cell proliferation in the absence of D-cyclins. Cell. 2004;118(4):477-491.

27. Furukawa Y. Cell cycle control genes and hematopoietic cell differentiation. Leuk Lymphoma. 2002;43(2):225-231.

28. Krek W, Ewen ME, Shirodkar S, Arany Z, Kaelin WG Jr, Livingston DM. Negative regulation of the growth-promoting transcription factor E2F-1 by stably bound cyclin A-dependent protein kinase. Cell. 1994;78(1): 161-172.
29. Santamaria D, Ortega S. Cyclins and CDKS in development and cancer: lessons from genetically modified mice. Front Biosci. 2006;11: $1164-1188$.

30. Dong LQ, Hu RL, Zhou FC. Liters of strong white tablets in the treatment of chemotherapy patients leukopenia attached: 58 cases reported. Chengdu University of Traditonal Medicine. 2004;27:54-54. Chinese.

31. Ai MH, Yu H, Xu YQ. Kidney Pei-yuan soup treatment of chemotherapy-induced leukopenia. Chinese Integrative Medicine Surgery. 2003;9:18-19. Chinese.

32. Li PX. Chinese medicine treatment of cancer chemotherapy leukopenia. Tianjin Traditional Chinese Medicine. 2004;21:174-176. Chinese.

33. Li XP, Chen Z, Wang WX. Chinese medicine treatment of chemotherapy leukopenia Meta-analysis. Shanghai Journal of Traditional Chinese Medicine. 2003;37:52-55. Chinese.

34. Tao MF, Yang WD, Wang JH. Ciwujia injection of the protective effects of radiation injury in mice bone marrow micro environment. Nanjing University of Traditional Chinese Medicine. 2004;20:75-177. Chinese.

35. Wang L, Wang Y. Experimental study for the effect of TSPG on the expression of IL-3 in hematopoietic stromal cells. Acta Anatomica Sinica. 2004;35(1):49-54.

36. Cheng JF, Zhang Y, He JR. Astragalus polysaccharides on mice chemotherapy white blood cells and bone marrow nucleated cells reduced. Chinese Journal of Modern Applied Pharmacy. 2003;5: 378-380. Chinese.

37. Lu Y, Zhong XY, Chen Y, Chen QG, Chen ZY, Lin DJ. Effect of ShenqiFuzheng injection of murine hematopoietic function chemo-therapy. Journal of Tropical Medicine. 2005;5:750-752. Chinese.

38. $\mathrm{He} \mathrm{DC,} \mathrm{He} \mathrm{H,} \mathrm{Wu} \mathrm{JP.} \mathrm{Chinese} \mathrm{herbal} \mathrm{compound} \mathrm{on} \mathrm{the} \mathrm{role} \mathrm{of} \mathrm{radiation}$ damage in mouse bone marrow cell cycle gene and adhesion molecule expression. Medicine. 2004;11:980-981. Chinese.

39. Li Z, Zang YH, Li J. The Effect of the leukemia K562 cell cycle and apoptosis rate and membrane fluidity. Cancer Prevention and Treatment. 2004;11:55-57. Chinese.

40. Chai XY, Wu WG, Liu WS. Anti-cancer effects about pena of $\mathrm{XIAO}$ JI-decoction plus huacilansu on lewis lung cancer cell in mices. China Journal of Chinese Materia Medica. 2004;2:58-60. Chinese.

41. Liang Y, Chen ZX, Qiu HM. Disinfect drinking leukemia K562 cell proliferation cycle and apoptosis in experimental studies, the raising of the positive impact. Traditional Chinese Medicine. 2004;10(1):44-47. Chinese.

42. Tang FA, Gong ZJ, Zhou H, et al. Gene expression analysis of the implanted-tumor of nasopharyngeal carcinoma treating by YIQIJIEDU granule using human cancer cDNA array. Practical Preventive Medicine. 2004;11:637-640.

43. Zhu M. The Medical Classic of the Yellow Emperor. Beijing: Foreign Languages Press; 2011.

44. ShenNong Ben Cao Jing. Shen Nongs herbal Classic. Western Han Dynasty. Chinese.

45. Shen YH, Chen CX, Xu ZY. Effect of ShuanghuangShengbaigranule on radiotherapy or chemotherapy induced leukopenia in mice. Zhongguo Zhong Yao Za Zhi. 2005;30(16):1275-1279. Chinese.

46. Shen YH, Chen CX, Xu ZY. Experimental research of ShuanghuangShengbaigranule on hematopoietic cells of leucopenia model mice. Zhongguo Zhong Yao Za Zhi. 2006;31(9):754-759. Chinese.

47. Xu ZY, Zhu YW, Zhou WD. Clinical and experimental study on effect of Shuanghuangshengbaigranule on myelosuppression induced by chemotherapy and ultrastructure observation of bone marrow in mice. Zhongguo Zhong Xi Yi Jie He Za Zhi. 2001;21(5):328-331. Chinese. 
OncoTargets and Therapy

\section{Publish your work in this journal}

OncoTargets and Therapy is an international, peer-reviewed, open access journal focusing on the pathological basis of all cancers, potential targets for therapy and treatment protocols employed to improve the management of cancer patients. The journal also focuses on the impact of management programs and new therapeutic agents and protocols on
Dovepress

patient perspectives such as quality of life, adherence and satisfaction. The manuscript management system is completely online and includes a very quick and fair peer-review system, which is all easy to use. Visit http://www.dovepress.com/testimonials.php to read real quotes from published authors.

Submit your manuscript here: http://www.dovepress.com/oncotargets-and-therapy-journal 